\title{
ANALISIS INVESTASI EMAS DAN SAHAM SEBAGAI BENTUK KEPUTUSAN INVESTASI (STUDI KASUS KARYAWAN BANK MANDIRI CABANG PADANG)
}

\author{
Yuliana Gani, Yulia Syafitri. SE, N.SI, AK, Nova Begawati, SE.MM \\ Universitas Ekasakti
}

\begin{abstract}
This study aims to influence the investment of gold on investment decisions on the employees of Bank Mandiri branch of Padang, To determine the effect of stock investment on investment decisions on employees of Bank Mandiri branch Padang, To determine the effect of gold and stock investment on investment decisions on employees of Bank Mandiri branch Padang and For knowing which investment decisions are most preferred by employees of Bank Mandiri branch Padang. Data collection methods used in this research is by using research lapanga and research library. Methods of data analysis in this study using multiple regression. The results of this study indicate that: 1) The test results $t$ Investment Gold Investment Decision obtained $t$ value of 2.152 is greater than $t$ table of 2.002 and the value of sig of 0.000 smaller than 0.05 so that Gold Investment variables significantly influence the Investment Decision, 2) The result of t test of Investment Tests on Investment Decision found t value equal to 13,498 bigger than t table equal to 2,002 and value of sig equal to 0,001 less than 0,05 so variable of Investment of Saham has significant effect to Investment Decision 3) Result of F test test Gold Investment and Stock Investment to Investment Decision found the value of $F$ arithmetic equal to 123,233 bigger than F table equal to 4,00 and sig value equal to 0.000 less than 0,05 so that variable of Gold Investment and Investment of Stock have significant effect to Investment Decision 4) Based on the answers given by employees quizoner of PT. Bank Mandiri branch of Padang is known type of investment is the most other selected by 25 respondents, gold by 20 respondents and shares of 15 respondents. (YG)
\end{abstract}

Keywords : Gold Investment, Stock Investment, Investment Decision. 


\begin{abstract}
ABSTRAK
Penelitian ini bertujuan untuk mengetahui pengaruh investasi emas terhadap keputusan investasi pada karyawan bank Mandiri cabang Padang, Untuk mengetahui pengaruh investasi saham terhadap keputusan investasi pada karyawan bank Mandiri cabang Padang, Untuk mengetahui pengaruh investasi emas dan saham terhadap keputusan investasi pada karyawan bank Mandiri cabang Padang dan Untuk mengetahui keputusan investasi manakah yang paling banyak dipilih oleh karyawan bank Mandiri cabang Padang. Metode pengumpulan data yang digunakan dalam penelitan ini yaitu dengan menggunakan riset lapangan dan riset pustaka. Metode analisis data dalam penelitian ini menggunakan regresi berganda. Hasil penelitian ini menunjukka bahwa: 1) Hasil pengujian uji t Investasi Emas terhadap Keputusan Investasi didapati nilai t hitung sebesar 2,152 lebih besar dari t tabel sebesar 2,002 dan nilai sig sebesar 0,000 lebih kecil dari 0,05 sehingga variabel Investasi Emas berpengaruh signifikan terhadap Keputusan Investasi, 2) Hasil pengujian uji t Investasi Saham terhadap Keputusan Investasi didapati nilai t hitung sebesar 13,498 lebih besar dari t tabel sebesar 2,002 dan nilai sig sebesar 0,001 lebih kecil dari 0,05 sehingga variabel Investasi Saham berpengaruh signifikan terhadap Keputusan Investasi 3) Hasil pengujian uji F Investasi Emas dan Investasi Saham terhadap Keputusan Investasi didapati nilai $\mathrm{F}$ hitung sebesar 123,233 lebih besar dari $\mathrm{F}$ tabel sebesar 4,00 dan nilai sig sebesar 0,000 lebih kecil dari 0,05 sehingga variabel Investasi Emas dan Investasi Saham berpengaruh signifikan terhadap Keputusan Investasi 4) Berdasarkan jawaban kuisoner yang diberikan karyawan PT. Bank Mandiri cabang Padang diketahui jenis investasi yang paling banyak dipilih adalah investasi lainnya sebesar 25 responden, investasi emas sebesar 20 responden dan investasi saham sebesar 15 responden. (YG)
\end{abstract}

Kata Kunci : Investasi Emas, Investasi Saham, Keputusan Investasi. 


\section{PENDAHULUAN}

Orang kaya sekalipun masih butuh investasi untuk melindungi asetnya dari penurunan nilai akibat inflasi. Tentunya, kepentingan untuk berinvestasi akan semakin tinggi bagi mereka yang hidupnya bergantung kepada gaji bulanan saja. Sangat tidak bijaksana jika membiarkan harta kekayaan yang dimiliki hanya tertanam di dalam penyimpanan pribadi dan tidak diupayakan semaksimal mungkin untuk melindungi harta kekayaan tersebut dari inflasi. Karena dengan tidak berbuat sesuatu terhadap harta kekayaan, maka sebenarnya terjadi penyusutan terhadap harta kekayaan tersebut. Salah satu langkah yang baik untuk melindungi harta kekayaan mereka dari ancaman - ancaman dimasa yang akan datang dan agar bisa memperbaiki taraf hidup dimasa yang akan datang adalah investasi.

Investasi adalah penempatan uang atau dana dengan harapan untuk memperoleh tambahan atau keuntungan tertentu atas uang tersebut. Dalam berinvestasi berlaku hukum bahwa semakin tinggi keuntungan yang ditawarkan maka semakin tinggi pula resiko yang harus ditanggung investor. Investor bisa saja mengalami kerugian bahkan lebih dari itu bisa kehilangan semua modalnya. Oleh karena itu penting bagi investor untuk menentukan tujuannya dalam berinvestasi, sehingga dapat memutuskan jenis investasi apa yang akan dipilih.

Banyak jenis investasi yang bisa digunakan, namun di penelitian ini penulis membahas dua investasi yang mayoritas di gunakan para investor yaitu emas dan saham. Emas merupakan salah satu instrumen investasi yang banyak digunakan masyarakat. Hal ini disebabkan oleh nilai dari emas yang selalu meningkat dari waktu kewaktu. Walaupun peningkatan nilai tidak cenderung besar namun emas merupakan salah satu instrumen investasi jangka panjang yang patut dipertimbangkan. Proses pembelian dan penjualan emas tergolong gampang, ketika masyarakat hendak menjual emasnya hanya perlu melampirkan bukti pembelian emas tersebut. Dengan prosesnya yang gampang membuat emas menjadi pilihan primadona bagi masyarakat untuk berinvestasi.

Selain emas, investasi juga dapat berupa saham perusahaan yang sudah go publik. Saham diperjual belikan di Bursa Efek Indonesia setiap hari kerja dan telak dijamin transaksinya oleh otoritas jasa keuangan (OJK). Berinvestasi saham berbeda dengan emas, pada investasi emas masyarakat tidak dituntut memiliki ilmu pengetahuan yang luas mengenai pasar dan analisis investasi sedangkan investasi saham diperlukan pengetahuan tersebut. Ketika seseorang ingin berinvestasi saham ia harus mengerti bagaimana menilai pasar jika tidak ingin mendapatkan kerugian.

Pergerakan harga saham lebih dinamis dibandingkan harga emas, naik turunnya harga saham disebabkan banyak

faktor baik internal maupun external. Dengan memiliki pengetahuan yang memadai investor akan memperoleh laba yang cukup besar dari hasil investasi saham, laba tersebut baik berupa capital gain ataupun deviden. Bursa Efek Indonesia adalah tempat perusahaan memperjual belikan saham kepemilikan perusahaannya, saham ini kemudian dibeli oleh investor melalui nstrumen instrumen yang ada. Dengan tersedianya kemudahan

dalam membeli saham pada Bursa Efek Indonesia membuat investor tertarik dalam melakukan pembelian saham. Pembelian saham merupakan salah satu jenis investasi yang menjanjikan karena memberikan deviden kepada pemiliknya setiap periode.

Dari dua penjelasan instrumen investasi diatas, maka seseorang harus mengambil keputusan untuk berinvestasi di instrumen mana. Keputusan investasi harus dipertimbangkan dengan matang agar tujuan untuk berinvestasi tercapai. Keputusan investasi ini sering juga disebut sebagai capital budgeting yakni keseluruhan proses perencanaan dan 
pengambilan keputusan mengenai pengeluaran dana yang jangka waktu kembalinya dana tersebut melebihi satu tahun atau berjangka panjang.Keputusan investasi menyangkut penilaian atas suatu usulan investasi atau pemilihan satu atau beberapa dari alternatif-alternatif usulan yang tersedia. Pemilihan keputusan investasi disebabkan oleh banyak faktor, salah satunya adalah kemampuan untuk melakukannya. Pemilihan investasi emas dan saham memiliki kelemahan dan kelebihan masing masing, dengan mempertimbangkan kelemahan dan kelebihannya seseorang akan dapat memilih investasi yang akan dipilih sesuai kemampuannya.

Dengan mempertimbangkan kelebihan dan kelemahan investasi emas dan saham, investasi emas banyak dilakukan oleh masyarakat awam sedangkan investasi saham hanya dilakukan oleh orang orang tertentu yang mengerti mengenai saham tersebut salah satunya adalah karyawan Bank khususnya Bank Mandiri. Bank Mandiri merupakan salah satu bank milik negara Indonesia dan memiliki cabang salah satunya di kota Padang, sebagai bank plat merah bank Mandiri merekrut karyawan yang berkompeten dibidangnya. Karyawan bank mandiri terutama yang telah menjadi pegawai tetap memiliki gaji dan tunjangan yang cukup besar setiap bulannya. Dengan memiliki gaji dan tunjangan yang cukup besar, karyawan bank Mandiri termotivasi untuk berinvestasi pada uangnya. Hal yang biasa dilakukan adalah dengan menyimpan uang di bank dengan mengharapkan bunga bank, atau dengan melakukan deposito.

Bank Mandiri merupakan salah satu bank yang memiliki rekening khusus untuk pemain di Bursa Efek Indonesia. Akun bank ini sebagai penempatan dana nasabah yang ingin melakukan transaksi di Bursa Efek Indonesia. Dengan adanya fasilitas tersebut, Bank Mandiri terlebih dahulu melakukan peatihan terhadap karyawannya untuk melakukan investasi ke Bursa Efek Indonesia. Pelatihan ini bertujuan agar memudahkan proses promosi fasilitas akun tersebut kepada masyarakat.

Hasil wawancara yang dilakukan penulis pada karyawan Bank Mandiri Cabang Padang menjelaskan investasi dengan tabungan atau deposito memberikan hasil yang sedikit dan nilai tersebut berada dibawah standar bunga bank Indonesia. Pilihan investasi lainnya dengan berinvestasi pada emas, bervesatasi pada emas dilakukan karena emas dapat dijual kapanpun dan menjualnya cukup mudah. Bagi karyawan bank Mandiri yang memiliki kemampuan untuk menganalisa pasar dan memiliki tabungan yang lebih, memilih berinvestasi dalam bentuk saham. Saham dipilih karena dapat memberikan hasil yang lebih berupa deviden ataupun capital gain. Investasi saham dilakukan dengan melihat pergerakan harga saham pada perusahaan yang terdaftar di Bursa Efek Indonesia. Analisa awal sebelum pembelian saham penting dilakukan agar tidak terjadi kerugian (Capital Lost).

Dengan pertimbangan mengenai investasi emas dan saham sudah selayaknya karyawan Bank Mandiri Cabang Padang memilih investasi dalam bentuk saham dibandingkan emas mengingat keuntungan yang diperoleh. Hal tersebut tidak lepas dari kemudahan yang diberikan Bank Mandiri dalam berinvestasi dan kemampuan karyawannya yang dapat dikategorikan pegawai terpilih.Berdasarkan uraian di atas, penulis tertarik untuk melakukan penelitian dengan judul "Analisis Investasi Emas Dan Saham Sebagai Bentuk Keputusan Investasi (Studi Kasus Karyawan Bank Mandiri Cabang Padang)".

Penelitian terdahulu :

\section{Anindito Putra (2013) Analisis Perbandingan Investasi Saham, Emas, Dan Obligasi pada Bursa Efek Indonesia tahun 2010 - 2012.} menjelaskan bahwa dari ketiga instrumen investasi selama periode penelitian adalah sebagai berikut, menurut metode Sharpe obligasi 
adalah instrumen investasi terbaik dengan nilai 0,05329 , menurut metode Treynor emas adalah intrumen investasi terbaik dengan nilai 0,00227,dan menurut metode jensen emas adalah instrumen terbaik dengan nilai 0,00029. Dapat disimpulkan bahwa selama periode penelitian emas adalah jenis instrumen investasi terbaik yang kemudian diikuti oleh obligasi pada peringkat keduadan saham pada peringkat ketiga.

\section{METODE PENELITIAN}

1. Metode Pengumpulan Data

Metode pengumpulan data yang digunakan dalam penelitian ini adalah dengan menggunakan angket, yaitu teknik pengumpulan data yang dilakukan dengan cara memberikan seperangkat pertanyaan kepada karyawan Bank Mandiri cabang Padang.

2. Teknik Pengumpulan Data
Teknik pengumpulan data yang digunakan adalah riset lapangan dan kuesioner.

3. Jenis dan Sumber Data Jenis data adalah data kualitatif dengan sumber data primer.

4. Populasi dan Sampel

Penelitian ini memiliki populasi sebanyak 149 orang dengan sampel sebanyak 60 orang dengan rumus slovin.

5. Uji Instrumen Penelitian

Penelitian ini menggunakan uji validitas dan uji reliabilitas.

6. Uji Asumsi Klasik

Uji yang digunakan ada 3 (tiga) yaitu uji normalitas, uji multikolinearitas dan uji heteroskedastisitas.

7. Metode Analisis Data

Metode yang digunakan adalah analisis deskriptif, analisa regresi linear berganda dan koefisien determinasi.

8. Metode Pengujian Hipotesis Hipotesis diuji dengan 2 cara yaitu uji $\mathrm{T}$ (parsial) dan uji $\mathrm{F}$ (simultan).

\section{HASIL DAN PEMBAHASAN}

Deskripsi Responden Berdasarkan Jenis Kelamin
\begin{tabular}{|c|c|c|}
\hline Jenis Kelamin & Jumlah & Persentase \% \\
\hline Pria & 15 & $25 \%$ \\
\hline Wanita & 45 & $75 \%$ \\
\hline Total & 60 & $100 \%$ \\
\hline Sumber; Data Primer yang diolah
\end{tabular}

Deskripsi Responden Berdasarkan Usia

\begin{tabular}{|c|c|c|}
\hline Usia & Jumlah & Persentase \% \\
\hline $17-23$ & 17 & $28,33 \%$ \\
\hline $24-30$ & 15 & $25 \%$ \\
\hline $31-37$ & 13 & $21,66 \%$ \\
\hline $38-44$ & 10 & $16,66 \%$ \\
\hline $45-51$ & 3 & $5 \%$ \\
\hline$>51$ & 2 & $3 \%$ \\
\hline Total & 60 & $100 \%$ \\
\hline
\end{tabular}

Sumber; Data Primer yang diolah 
Deskripsi Responden Berdasarkan Penghasilan

\begin{tabular}{|c|c|c|}
\hline Penghasilan & Jumlah & Persentase \% \\
\hline$<1.000 .000$ & 0 & $0 \%$ \\
\hline 1.000 .000 s.d 3.000 .000 & 37 & $61,66 \%$ \\
\hline 4.000 .000 s.d 6.000 .000 & 23 & $38,33 \%$ \\
\hline 7.000 .000 s.d 9.000 .000 & 0 & $0 \%$ \\
\hline$>93.000 .000$ & 0 & $0 \%$ \\
\hline Total & 60 & $100 \%$ \\
\hline
\end{tabular}

Sumber; Data Primer yang diolah

Deskripsi Responden Berdasarkan Investasi

\begin{tabular}{|c|c|c|}
\hline Pekerjaan & Jumlah & Persentase \% \\
\hline Emas & 20 & $33,33 \%$ \\
\hline Saham & 15 & $25 \%$ \\
\hline Lainnya & 25 & $41,66 \%$ \\
\hline Total & 60 & $100 \%$ \\
\hline
\end{tabular}

Sumber; Data Primer yang diolah

Descriptive Statistik

Statistik Deskriptif Variabel Investasi Emas ( $\left.\mathrm{X}_{1}\right)$

\begin{tabular}{|l|r|r|r|r|r|}
\hline & $\mathrm{N}$ & Minimum & Maximum & \multicolumn{1}{|c|}{ Mean } & Std. Deviation \\
\hline x101 & 60 & 3,00 & 5,00 & 4,0500 &, 64899 \\
x102 & 60 & 3,00 & 5,00 & 4,0667 &, 66042 \\
x103 & 60 & 3,00 & 5,00 & 4,0667 &, 70990 \\
x104 & 60 & 3,00 & 5,00 & 3,7833 &, 49030 \\
x105 & 60 & 3,00 & 5,00 & 4,0167 &, 59636 \\
x106 & 60 & 3,00 & 5,00 & 3,8167 &, 53652 \\
x107 & 60 & 3,00 & 5,00 & 4,0167 &, 59636 \\
x108 & 60 & 3,00 & 5,00 & 3,8667 &, 72408 \\
x109 & 60 & 3,00 & 5,00 & 3,9833 &, 50394 \\
x110 & 60 & 3,00 & 5,00 & 3,7833 &, 61318 \\
x111 & 60 & 3,00 & 5,00 & 3,9833 &, 62414 \\
x112 & 60 & 3,00 & 5,00 & 4,0667 &, 68561 \\
x1 & 60 & 30,00 & 49,00 & 39,4500 & 4,29988 \\
Valid N (listwise) & 60 & & & & \\
\hline
\end{tabular}

Sumber : Data Primer yang Diolah

Dari tabel statistik deskriptif variabel X1 diketahui nilai terendah pada setiap pertanyaan adalah 3 dan tertinggi adalah 5, nilai akumulasi variabel Investasi Emas $\left(\mathrm{X}_{1}\right)$ terendah adalah 30 dan tertinggi 49. Nilai rata rata tertinggi terdapat pada item perntanyaan ke 2,3 dan 12 dengan nilai 4,0667 dan yang terendah adalah item pertanyaan ke 4 dan 10 dengan nilai 3,7833 sedangkan untuk rata rata total jawaban variabel Investasi Emas $\left(\mathrm{X}_{1}\right)$ adalah 39,45. Standar deviasi tertinggi terdapat pada item pertanyaan ke 8 dengan nilai 0,72408 dan terendah pada item pertanyaan ke 9 dengan nilai 0,50394 . 
Statistik Deskriptif Variabel Investasi Saham $\left(\mathbf{X}_{2}\right)$

\begin{tabular}{|l|r|r|r|r|r|}
\hline & $\mathrm{N}$ & Minimum & Maximum & \multicolumn{1}{|c|}{ Mean } & Std. Deviation \\
\hline x201 & 60 & 3,00 & 5,00 & 4,0833 &, 80867 \\
x202 & 60 & 3,00 & 5,00 & 3,7333 &, $73338 \mathbf{I}$ \\
x203 & 60 & 3,00 & 5,00 & 4,1000 &, 68147 \\
x204 & 60 & 3,00 & 5,00 & 4,0000 &, $63779 \mathbf{I}$ \\
x205 & 60 & 3,00 & 5,00 & 4,1333 &, 70028 \\
x206 & 60 & 3,00 & 5,00 & 3,8833 &, 58488 \\
x207 & 60 & 3,00 & 5,00 & 3,7833 &, $61318 \mathbf{I}$ \\
x208 & 60 & 3,00 & 5,00 & 3,7500 &, 65419 \\
x209 & 60 & 3,00 & 5,00 & 3,8833 &, $55515 \mathbf{I}$ \\
x210 & 60 & 3,00 & 5,00 & 3,9000 &, 68147 \\
x211 & 60 & 3,00 & 5,00 & 4,0167 &, 62414 \\
x212 & 60 & 3,00 & 5,00 & 3,8667 &, $59565 \mathbf{I}$ \\
x2 & 60 & 31,00 & 55,00 & 40,3667 & 5,84247 \\
Valid N (listwise) & 60 & & & & \\
\hline
\end{tabular}

Sumber : Data Primer yang Diolah

Dari tabel statistik deskriptif variabel X2 diketahui nilai terendah pada setiap pertanyaan adalah 3 dan tertinggi adalah 5, nilai akumulasi variabel Investasi Saham $\left(\mathrm{X}_{2}\right)$ terendah adalah 31 dan tertinggi 55. Nilai rata rata tertinggi terdapat pada item perntanyaan ke 5 dengan nilai 4,1333 dan yang terendah adalah item pertanyaan ke 2 dengan nilai 3,7333 sedangkan untuk rata rata total jawaban variabel Investasi Saham $\left(\mathrm{X}_{2}\right)$ adalah 40,3667. Standar deviasi tertinggi terdapat pada item pertanyaan ke 1 dengan nilai 0,80867 dan terendah pada item pertanyaan ke 9 dengan nilai 0,55515 .

Statistik Deskriptif Variabel Keputusan Investasi (Y)

\begin{tabular}{|l|r|r|r|r|r|}
\hline & $\mathrm{N}$ & Minimum & Maximum & \multicolumn{1}{c|}{ Mean } & Std. Deviation \\
\hline y1 & 60 & 3,00 & 5,00 & 3,9000 &, 68147 \\
y2 & 60 & 2,00 & 5,00 & 3,5833 &, 61868 \\
y3 & 60 & 3,00 & 5,00 & 3,9000 &, 60226 \\
y4 & 60 & 3,00 & 5,00 & 3,8833 &, 58488 \\
y5 & 60 & 3,00 & 5,00 & 4,0000 &, 66384 \\
y6 & 60 & 3,00 & 5,00 & 3,9333 &, 63424 \\
y7 & 60 & 3,00 & 5,00 & 4,1833 &, 56723 \\
y8 & 60 & 3,00 & 5,00 & 4,0167 &, 62414 \\
y9 & 60 & 3,00 & 5,00 & 3,9333 &, 57833 \\
y & 60 & 27,00 & 45,00 & 35,3333 & 4,22128 \\
Valid N (listwise) & 60 & & & & \\
\hline
\end{tabular}

Sumber : Data Primer yang Diolah

Dari tabel statistik deskriptif variabel $\mathrm{Y}$ diketahui nilai terendah pada setiap pertanyaan adalah 2 dan tertinggi adalah 5 , nilai akumulasi variabel Keputusan Investasi (Y) terendah adalah 27 dan tertinggi 45 . Nilai rata rata tertinggi terdapat pada item perntanyaan ke 7 dengan nilai 4,1833 dan yang terendah adalah item pertanyaan ke 2 dengan nilai 3,5833 sedangkan untuk rata rata total jawaban variabel Keputusan Investasi (Y) adalah 35,3333. Standar deviasi tertinggi terdapat pada item pertanyaan ke 1 dengan nilai 0,68147 dan terendah pada item pertanyaan ke 7 dengan nilai 0,56723 . 


\section{Uji Instrumen Penelitian \\ Uji Validitas}

Hasil Uji Validitas Variabel Investasi Emas $\left(\mathbf{X}_{1}\right)$

\begin{tabular}{|c|c|c|c|c|}
\hline & $\begin{array}{l}\text { Scale Mean if } \\
\text { Item Deleted }\end{array}$ & $\begin{array}{l}\text { Scale Variance } \\
\text { if Item Deleted }\end{array}$ & $\begin{array}{c}\text { Corrected Item- } \\
\text { Total } \\
\text { Correlation }\end{array}$ & $\begin{array}{l}\text { Cronbach's } \\
\text { Alpha if Item } \\
\text { Deleted }\end{array}$ \\
\hline $\mathrm{x} 101$ & 82,9000 & 77,786 &, 700 & ,773 \\
\hline x102 & 82,8833 & 76,308 & ,821 & ـ 767, \\
\hline x103 & 82,8833 & 77,291 & 675 & 772 \\
\hline x104 & 83,1667 & 80,887 & ,577 & ,783 \\
\hline x105 & 82,9333 & 80,775 &, 475 & ,784 \\
\hline x106 & 83,1333 & 79,711 & ,649 & ,779| \\
\hline x107 & 82,9333 & 78,673 & 680 & ,775 \\
\hline x108 & 83,0833 & 77,061 & 679 & ,771 \\
\hline x109 & 82,9667 & 80,270 & ,631 & ,780 \\
\hline $\mathrm{x} 110$ & 83,1667 & 77,768 & ,747 & ,772 \\
\hline x111 & 82,9667 & 80,406 & ,484 & ,783 \\
\hline x112 & 82,8833 & 79,257 & 532 & ,779 \\
\hline$x 1$ & 47,5000 & 25,305 & ,981 & ,892 \\
\hline
\end{tabular}

Sumber : Data Primer yang Diolah

Berdasarkan tabel uji validitas $\mathrm{X} 1$ seluruh pertanyaan variabel Investasi Emas dinyatakan valid dikarenakan seluruh nilai
Correlation berada diatas nilai $\mathrm{r}$ tabel $(0,25)$, dan seluruh item pernyataan dapat digunaan untuk pengujian selanjutnya.

\begin{tabular}{|l|r|r|r|r|}
\hline \multicolumn{2}{|c|}{ Hasil Uji Validitas pada Variabel Investasi Saham(X2) } \\
\hline & $\begin{array}{c}\text { Scale Mean if } \\
\text { Item Deleted }\end{array}$ & $\begin{array}{c}\text { Scale Variance } \\
\text { if Item Deleted }\end{array}$ & $\begin{array}{c}\text { Corrected Item- } \\
\text { Total } \\
\text { Correlation }\end{array}$ & $\begin{array}{c}\text { Cronbach's } \\
\text { Alpha if Item } \\
\text { Deleted }\end{array}$ \\
\hline x201 & 83,4167 & 96,518 &, 676 &, 654 \\
x202 & 83,7667 & 96,284 &, 771 &, 651 \\
x203 & 83,4000 & 98,990 &, 624 &, 662 \\
x204 & 83,5000 & 101,068 &, 502 &, 671 \\
x205 & 83,3667 & 99,287 &, 583 &, 664 \\
x206 & 83,6167 & 101,122 &, 548 &, 670 \\
x207 & 83,7167 & 99,766 &, 635 &, 665 \\
x208 & 83,7500 & 100,225 &, 554 &, 667 \\
x209 & 83,6167 & 101,935 &, 506 &, 673 \\
x210 & 83,6000 & 98,753 &, 642 &, 661 \\
x211 & 83,4833 & 102,864 &, 368 &, 678 \\
x212 & 83,6333 & 105,762 &, 147 &, 689 \\
x2 & 47,1333 & 23,846 &, 875 &, 852 \\
\hline
\end{tabular}

Berdasarkan tabel uji validitas $\mathrm{X} 2$ seluruh pertanyaan variabel Investasi Sahamdinyatakan valid dikarenakan seluruh nilai Correlation berada diatas nilai $r$ tabel $(0,25)$, dan seluruh item pernyataan dapat digunakan untuk pengujian selanjutnya. 
Hasil Uji Validitas pada Variabel Keputusan Investasi (Y)

\begin{tabular}{|l|r|r|r|r|}
\hline & $\begin{array}{c}\text { Scale Mean if } \\
\text { Item Deleted }\end{array}$ & $\begin{array}{r}\text { Scale Variance } \\
\text { if Item Deleted }\end{array}$ & $\begin{array}{c}\text { Corrected Item- } \\
\text { Total Correlation }\end{array}$ & $\begin{array}{c}\text { Cronbach's Alpha if } \\
\text { Item Deleted }\end{array}$ \\
\hline y1 & 66,7813 & 60,564 &, 603 &, 765 I \\
y2 & 66,7500 & 58,194 &, 698 &, 754 \\
y3 & 66,6875 & 57,835 &, 791 &, 750 I \\
y4 & 67,0000 & 60,774 &, 476 &, 768 \\
y5 & 66,7188 & 58,273 &, 784 &, 753 \\
y6 & 66,7188 & 58,402 &, 769 &, $753 \mathbf{I}$ \\
y7 & 66,5938 & 57,733 &, 764 &, 750 \\
y8 & 66,6563 & 58,362 &, 764 &, $753 \mathbf{I}$ \\
y9 & 66,4063 & 58,378 &, 826 &, 752 \\
y & 35,3125 & 16,415 & 1,000 &, 904 \\
\hline
\end{tabular}

Sumber : Data Primer yang Diolah

Berdasarkan tabel uji validitas $\mathrm{Y}$ seluruh pertanyaan variabel Keputusan Investasi dinyatakan valid dikarenakan seluruh nilai Correlation berada diatas nilai $r$ tabel $(0,25)$, dan seluruh item pernyataan dapat digunaan untuk pengujian selanjutnya.

Uji Reliabilitas

\begin{tabular}{|c|c|c|}
\hline Variabel & CA & Item \\
\hline $\mathrm{X} 1$ & 0,793 & 12 \\
\hline $\mathrm{X} 2$ & 0,688 & 12 \\
\hline $\mathrm{Y}$ & 0,780 & 9 \\
\hline \multicolumn{3}{|c|}{ Sumber : Data Primer yang Diolah }
\end{tabular}

Dari penyajian tabel uji reliabilitas maka seluruh variabel penelitian dinyatakan reliabel, dimana hasil perhitungan uji reliabilitas yang masing masing variabelnya menunjukan
Cronbach's Alpha lebih besar dari 0,25. Hal ini berarti keseluruhan variabel dapat digunakan untuk pengolahan data lebih lanjut.

Uji Asumsi Klasik

\section{Hasil Uji Normalitas}

\begin{tabular}{|ll|r|}
\hline & & Unstandardized Residual \\
\hline Normal Parameters & \\
& & 60 \\
& Mean & $0 \mathrm{E}-7$ \\
& Std. Deviation & 1,82947397 \\
Most Extreme Differences & Absolute & 092 \\
& Positive &, 075 \\
Kolmogorov-Smirnov Z & Negative &,- 092 \\
Asymp. Sig. (2-tailed) & &, 711 \\
\hline
\end{tabular}

Sumber : Data Primer yang Diolah

Dari tabel Uji Normalitas didapatkan nilai residual sebesar 0,692 lebih besar dari 0,05 dari nilai sampel sebesar 60 yang berarti data yang sedang diuji berdistribusi normal. Selain menggunakan tabel diatas, juga dapat dengan melihat P-Plot seperti gambar 4.1 dibawah ini : 


\section{P-Plot}

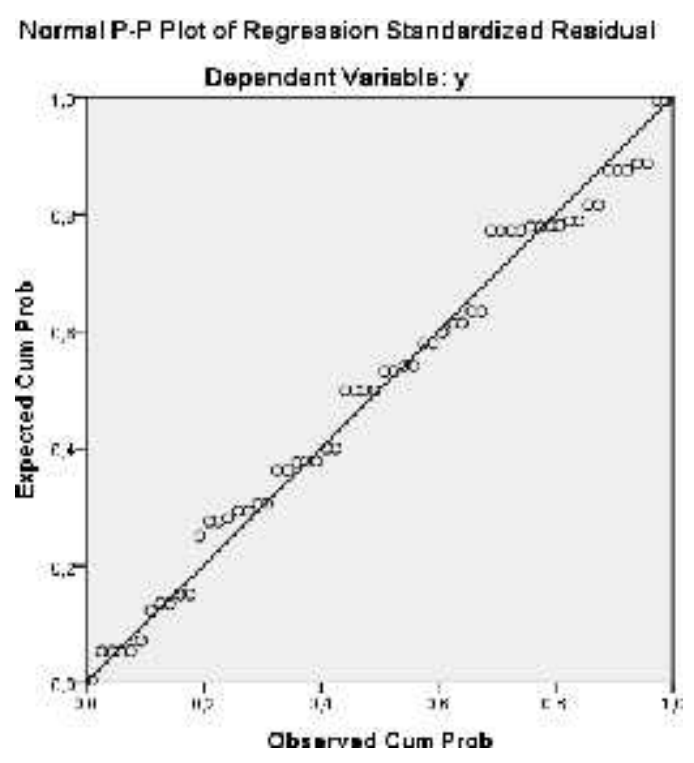

Sumber : Data Primer yang Diolah

Berdasarkan tampilan P-Plot dapat disimpulkan bahwa model regresi diketahui terlihat titik titik mengikuti dan memenuhi asumsi normalitas. mendekati garis diagonalnya sehingga

\section{Hasil Uji Multikolinearitas}

\begin{tabular}{|rr|r|r|}
\hline \multicolumn{2}{|l|}{ Model } & \multicolumn{2}{|c|}{ Collinearity Statistics } \\
\cline { 3 - 4 } & & Tolerance & \multicolumn{1}{c|}{ VIF } \\
\hline \multirow{3}{*}{1} & (Constant) & & \\
& x1 &, 849 & 1,177 \\
& x2 &, 849 & 1,177 \\
\hline
\end{tabular}

Sumber : Data Primer yang Diolah

Dari tabel Uji Multikolineraritas dapat disimpulkan bahwa semua variabel telah lolos dari uji multikolinearitas dikarenakan nilai VIF lebih kecil dari 10, yang berarti data yang digunakan terjadi multikolinearritas.

Hasil Uji Asumsi Heteroskedastisitas

\begin{tabular}{|rl|r|r|}
\hline Model & & \multicolumn{1}{c|}{$\mathrm{t}$} & \multicolumn{1}{c|}{ Sig. } \\
& & & \\
\hline \multirow{3}{*}{1} & (Constant) & $-1,484$ &, 143 \\
& $\mathrm{x} 1$ &, 725 &, 471 \\
& $\mathrm{x} 2$ & 2,325 &, 061 \\
\hline
\end{tabular}

Sumber : Data Primer yang Diolah

Dari tabel Uji Multikolineraritas dapat diketahui bahwa seluruh variabel yang memenuhi syarat uji heteroskedastisitas yang memiliki nilai sig besar dari 0,05 
Analisa Kuantitatif

Coefficients

\begin{tabular}{|rl|r|r|r|}
\hline Model & \multicolumn{2}{|c|}{ Unstandardized Coefficients } & \multicolumn{2}{|c|}{ Standardized Coefficients } \\
\cline { 3 - 5 } & (Constant) & B & Std. Error & \multicolumn{2}{|c|}{ Beta } \\
\hline \multirow{2}{*}{1} & $-1,135$ & 2,403 &, 841 \\
& x1 &, 825 &, 061 &, 134 \\
\hline
\end{tabular}

Sumber : Data Primer yang Diolah

Dari tabel di atas dapat ditarik persamaan regresinya sebagai berikut :

$\mathrm{Y}=-1,135+0,825 \mathrm{X}_{1}+0,097 \mathrm{X}_{2}$

Nilai konstanta sebesar $-1,135$ hal ini menunjukan bahwa jika terdapat penurunan variabel Investasi Emas $\left(\mathrm{X}_{1}\right)$ dan Investasi Saham $\left(\mathrm{X}_{2}\right)$ maka nilai Keputusan Investasi menurun sebesar 1,135 satuan.

1) Nilai koefisien regresi variabel Investasi Emas sebesar 0,825, berarti bahwa jika terjadi peningkatan variabel Investasi Emas sebesar satu satuan maka Keputusan Investasi PT. Bank Mandiri cabang Padang akan meningkat sebesar 0,825 atau $82,5 \%$. Kofesien bernilai positif artinya antara variabel Investasi Emas dan Keputusan Investasi berpengaruh positif. Kenaikan variabel Investasi Emas berakibat kenaikan pada variabel Keputusan Investasi.

2) Nilai koefisien regresi variabel Investasi Saham sebesar 0,097, berarti bahwa jika terjadi peningkatan variabel Investasi Saham sebesar satu satuan maka Keputusan Investasi PT. Bank Mandiri cabang Padang akan meningkat sebesar 0,097 atau 9,7\%. Kofesien bernilai positif artinya antara variabel Investasi Saham dan Keputusan Investasi berpengaruh positif. Kenaikan variabel Investasi Saham berakibat kenaikan pada variabel Keputusan Investasi.

Koefesien Determinasi

\begin{tabular}{|c|r|r|r|c|}
\hline Model & $\mathrm{R}$ & $\mathrm{R}$ Square & $\begin{array}{c}\text { Adjusted R } \\
\text { Square }\end{array}$ & $\begin{array}{c}\text { Std. Error of the } \\
\text { Estimate }\end{array}$ \\
\hline 1 &, $901^{\mathrm{a}}$ &, 812 &, 806 & 1,86129 \\
\hline
\end{tabular}

Berdasarkan tabel koefisien dan Investasi Saham $\left(\mathrm{X}_{2}\right)$ terhadap variabel determinasi diperoleh angka Adjusted R dependen Keputusan Investasi (Y) sebesar Square sebesar 0,806 atau $80,6 \%$, hal ini $\quad 0,806$ atau $80,6 \%$. Sedangkan sisanya menunjukan bahwa persentase sumbangan sebesar $19,4 \%$ dipengaruhi oleh variabel variabel independen Investasi Emas $\left(\mathrm{X}_{1}\right) \quad$ lain diluar penelitian ini.

Pengujian Hipotesis

Hasil Uji t

\begin{tabular}{|rl|r|r|}
\hline Model & \multicolumn{1}{|c|}{$\mathrm{t}$} & \multicolumn{1}{c|}{ Sig. } \\
& & & \\
\hline \multirow{2}{*}{1} & (Constant) &,- 472 &, 639 \\
& $\mathrm{x} 1$ & 13,498 &, 000 \\
& $\mathrm{x} 2$ & 2,152 &, 036 \\
\hline
\end{tabular}

Sumber : Data Primer yang Diolah 
Dari hasil uji $\mathrm{T}$ dengan menggunakan tingkat signifikansi $0,05(\alpha=$ $5 \%$ ) dan $t$ tabel pada signifikansi 0,05 uji dua arah dengan derajat kebebasan dfn-k-1 $=60-2-1=57$ (n adalah jumlah responden dan $\mathrm{k}$ adalah jumlah variabel bebas) dengan nilai t tabel sebesar 2,002 (lihat lampiran tabel). Hasil uji t dapat dilihat pada output SPSS dari tabel 4.14. diatas diketahui sebagai berikut :

a. Nilai thitung dari variabel Investasi Emas adalah sebesar 13,498 yang nilainya lebih besar dari nilai t tabel sebesar 2,002. Sehingga t hitung $>t$ tabel dan nilai sig perhitungan yang diperoleh adalah sebesar $0,000<$ 0,05 jadi $\mathrm{H}_{\mathrm{o}}$ ditolak $\mathrm{H}_{\mathrm{a}}$ diterima.
Dengan demikian dapat disimpulkan bahwa Investasi Emas secara individual berpengaruh signifikan positif terhadap Keputusan Investasi.

b. Nilai t hitung dari variabel Investasi Saham adalah sebesar 2,152 yang nilainya lebih besar dari nilai t tabel sebesar 2,002. Sehingga t hitung $>t$ tabel dan nilai sig perhitungan yang diperoleh adalah sebesar $0,036<$ 0,05 jadi $\mathrm{H}_{\mathrm{o}}$ ditolak $\mathrm{H}_{\mathrm{a}}$ diterima. Dengan demikian dapat disimpulkan bahwa Investasi Saham secara individual berpengaruh signifikan positif terhadap Keputusan Investasi.

ANOVA

\begin{tabular}{|c|c|c|c|c|c|}
\hline Model & Sum of Squares & $\mathrm{df}$ & Mean Square & $\mathrm{F}$ & Sig. \\
\hline Regression & 853,862 & 2 & 426,931 & 123,233 &, $000^{\mathrm{b}}$ \\
\hline Residual & 197,472 & 57 & 3,464 & & \\
\hline Total & 1051,333 & 59 & & & \\
\hline
\end{tabular}

Dari tabel annova diketahui nilai $\mathrm{F}$ hitung 123,233 yang lebih besar dar nilai $\mathrm{F}$ tabel sebesar 4,00 dan nilai sig yang dihasilkan dari perhitungan adalah 0,000 yang lebih kecil dari $\alpha$ yang digunakan sebesar 5\%. Dengan demikian dapat

\section{KESIMPULAN DAN SARAN}

\section{KESIMPULAN}

Berdasarkan hasil analisis dan pembahasan mengenai pengaruh Investasi Emas $\left(\mathrm{X}_{1}\right)$ dan Investasi Saham $\left(\mathrm{X}_{2}\right)$ terhadap Keputusan Investasi (Y), maka dapat ditarik kesimpulan sebagai berikut :

1. Hasil pengujian uji t Investasi Emas terhadap Keputusan Investasi didapati nilai t hitung sebesar 2,152 lebih besar dari t tabel sebesar 2,002 dan nilai sig sebesar 0,000 lebih kecil dari 0,05 sehingga variabel Investasi Emas berpengaruh signifikan terhadap Keputusan Investasi. disimpulkan variabel Investasi Emas $\left(\mathrm{X}_{1}\right)$ dan Investasi Saham $\left(\mathrm{X}_{2}\right)$ secara simultan / bersama-sama berpengaruh signifikan terhadap Keputusan Investasi PT. Bank Mandiri cabang Padang.

2. Hasil pengujian uji $\mathrm{t}$ Investasi Saham terhadap Keputusan Investasi didapati nilai $\mathrm{t}$ hitung sebesar 13,498 lebih besar dari $\mathrm{t}$ tabel sebesar 2,002 dan nilai sig sebesar 0,001 lebih kecil dari 0,05 sehingga variabel Investasi Saham berpengaruh signifikan terhadap Keputusan Investasi.

3. Hasil pengujian uji F Investasi Emas dan Investasi Saham terhadap Keputusan Investasi didapati nilai F hitung sebesar 123,233 lebih besar dari $\mathrm{F}$ tabel sebesar 4,00 dan nilai sig sebesar 0,000 lebih kecil dari 0,05 sehingga variabel Investasi 
Emas dan Investasi Saham berpengaruh signifikan terhadap Keputusan Investasi.

4. Berdasarkan jawaban kuisoner yang diberikan karyawan PT. Bank Mandiri cabang Padang diketahui jenis investasi yang paling banyak dipilih lainnya sebesar 25 responden, emas sebesar 20 responden dan saham sebesar 15 responden.

\section{SARAN}

Berdasarkan kesimpulan di atas, dapat dikemukakan beberapa rekomendasi yang diharapkan dapat bermanfat bagi perusahaan atau pihak lain yang berkepentingan. Adapun saran yang diberikan, antara lain :

1. Bagi PT. Bank Mandiri cabang Padang

Dari hasil penelitian menunjukkan bahwa karyawan bank mandiri masih banyak berinvestasi di jenis emas dan lainnya maka disarankan agar karyawan Bank Mandiri mulai beralih ke saham karena perkembangan pasar modal yang sedang berlangsung saat ini membawa manfaat yang lebih besar bagi perekonomian nasional dan pertumbuhan ekonomi asalkan harus lebih banyak masyarakat domestik yang memanfaatkan pasar modal sebagai tempat menyimpan kekayaannya. Sebab semakin besar partisipasi masyarakat domestik, maka pertumbuhan di pasar modal akan semakin banyak meningkatkan kekayaan masyarakat sehingga akhirnya diharapkan semakin mampu menggerakkan konsumsi dan pertumbuhan ekonomi juga diharapkan bisa mengurangi resiko sudden capital flow.

2. Bagi akademik

Diharapkan penelitian saya ini bisa menjadi pertimbangan untuk akademik dalam investasi dan bagi peneliti selanjutnya yang akan meneliti tentang keputusan Investasi untuk menambah variasi variabel yang mempengaruhi Keputusan Investasi, dan objek yang di teliti diperluas tidak hanya di PT. Bank Mandiri cabang Padang.

\section{DAFTAR PUSTAKA}

Agussalim Manguluang, 2015. Statistik Lanjutan, Ekasakti Press, Padang

Ahmad. 2015. Analisis Manajemen Investasi Bisnis. Jakarta : Salemba Empat.

Akbar, A. (2013). Easy Planning: Hidup Sejahtera Sekarang dan Nanti. Jakarta: Noura Books.

Anindito Putra (2013) Analisis Perbandingan Investasi Saham, Emas, Dan Obligasi

Anita Anita (2015) Analisis Komparasi Investasi Logam Mulia Emas Dengan Saham Perusahaan Pertambangan di Bursa Efek Indonesia 2010-2014

Anthanasius, Thomas. 2012. Panduan Berinvestasi Saham. Jakarta : PT Gramedia.

Apriyanti, Maya. 2012. Anti Rugi Dengan Berinvestasi Emas. Yogyakarta : Pustaka Baru Press. 
Ardianto (2016) Saham Sebagai Pondasi Investasi

Arikunto, Suharsimi. 2012. Prosedur Penelitian. Jakarta : PT Rineka Cipta.

Asri Nur Wahyuni (2014) Analisis Perbandingan Kinerja Investasi Emas Dan Investasi Saham Selama Masa Inflasi 1994 - 2013

Bambang dan Lina. 2014. Metodologi Penelitian Kuantitatif. Jakarta : Rajawali Pers.

Elton dan Gruber. 2013. Modern Portfolio Theory and Investment Analysis. Terjemahan Ari Kusumanegara. Jakarta : Gramedia.

Fatati Nuryana (2014) Analisis Pemilihan Instrumen Investasi Bisnis Emas, Valuta Asing Dan Saham

Ghozali, Imam. 2011. Aplikasi Analisis Multivariate Dengan Program IBM. SPSS 19 (edisi kelima.) Semarang: Universitas Diponegoro.

Hananto, L. 2011. Untuk Indonesia Yang Kuat: 100 Langkah Untuk Tidak Miskin. Jakarta: Literati.

Halim, Abdul dalam Irham Fahmi. 2012. Manajemen Keuangan Bisnis. Bogor : Ghalia Indonesia.

Hariyani, Iswi; S.H., M.H. 2013.Pasar Uang \& Pasar Valas. Jakarta: Penerbit PT Gramedia Pustaka Utama.

Hartono. 2016.) Pertimbangan Return Dan Risiko Dalam Keputusan Investasi

Isnaini, Rahmat. 2011. Investasi di Reksa Dana. Jakarta : Sinar Grafika.

Jere dan Naning. 2013. Shopping Saham Modal Sejuta. Jakarta : PT Elex Media Komputindo

Jones dalam Rahmat Isnaini. 2011. Teknik Dasar Investasi. Jakarta : Erlangga.

Kasmir dan Jakfar. 2012. Studi Kelayakan Bisnis. Jakarta : Kencana.

Nela Safelia. 2013. Konsep Dasar Keputusan Investasi Dan Portfolio

Priyanto, Duwi. 2012. Cara Kilat Belajar Analisis Data Dengan SPSS 20.00. Yogyakarta : Media Kom.

Putra, Anindito. 2013. Analisis Perbandingan Investasi Saham, Emas, dan Obligasi.Skripsi.

Rachman, Muchammad Rizal. 2010. Analisis Investasi Terhadap Tingkat Kesejahteraan dan Pertumbuhan Ekonomi di Kabupaten Gresik, Sidoarjo, dan Pasuruan. Skripsi.

Rifan Finan. 2013. Investasi Emas di Indonesia

Riyanto, Bambang. 2007. Pengantar Pasar Modal. Jakarta : Rineka Cipta. 
Rudianto. 2017. Evaluasi Kinerja 2016 dan Prediksi Kinerja Investasi 2017

Sari dan Simanggusong. 2015. Hukum Dalam Ekonomi Edisi Revisi. Jakarta : Grasindo.

Sugiyono. 2014. Metodologi Penelitian Kuantitatif, Kualitatif, dan R\&D. Bandung : CV Alfabeta.

Susilo, Bambang. 2009. Pasar Modal. Yogyakarta : Samudra Biru.

Tandelilin, Eduardus.2010.Portofolio dan Investasi.Yogyakarta: Kanisius.

Triyanti, Ari. 2012. Catatan Investasi dan Pasar Modal. Jakarta : Elex Media Komputindo.

Widoatmodjo, Sawidji. 2012. Cara Sehat Investasi di Pasar Modal. Jakarta : PT Jurnalindo Aksara Grafika.

Wijaya, Yudhi. 2013. Analisis Investasi dalam Bentuk Saham dan Emas Sejak Dini Sebagai Modal di Masa Depan Pada Masyarakat Kota Padang. Skripsi.

http://www.investasiemas.id/2016/12/investasi-emas-makin-profit-jika-gunakanindikator-ini.html (diakses pada tanggal 06 oktober 2017) 